\title{
Exploring the relationship between health status and simulated patient-care scenario performance among experienced paramedics.
}

Mathieu Tremblay ( $\sim$ mathieu_tremblay2@uqar.ca )

Université du Québec à Rimouski https://orcid.org/0000-0002-9507-9051

Wayne J. Albert

University of New Brunswick

Steven L. Fischer

University of Waterloo

Eric Beairsto

Medavie Blue Cross NB

Michel J. Johnson

Universite de Moncton

\section{Research article}

Keywords: Patient Simulator, Work Physiology, Occupational Performance, Health Status

Posted Date: January 2nd, 2020

DOI: https://doi.org/10.21203/rs.2.19945/v1

License: (c) (i) This work is licensed under a Creative Commons Attribution 4.0 International License. Read Full License

Version of Record: A version of this preprint was published at Work on September 8th, 2022. See the published version at https://doi.org/10.3233/WOR-211033. 


\section{Abstract}

BACKGROUND: It is well known that health status of paramedics may be altered by their job demands. However, it is unknown whether health conditions have a negative impact on occupational performance. The goal of this study was to explore whether a paramedic's health status affects performance during a patient-care simulation. More precisely, this paper aims to identify which health conditions (i.e., cardiovascular diseases (CVD), musculoskeletal disorders (MSD), post-traumatic stress disorders (PTSD), generalized anxiety disorders (GAD)) could be associated with negative performance.

METHODS: Nineteen paramedics aged $38.2 \pm 8.6$ years old with $15.0 \pm 8.7$ years of paramedic experience participated in this study. Participants completed two assessments: i) health conditions measurements and ii) patient-care simulation. Heart rate variability (HRV), an indicator of vagal activity was collected during the patient-care simulation. The simulation was used in order to challenge experienced paramedics in a realistic setting. Based on the provincial standard of New Brunswick, an experienced paramedic instructor graded (passed or failed) the patient-care simulation using the provincial standard charts, videos and data from manikin.

RESULTS: The current study suggests that only paramedics with self-reported elevated symptoms of PTSD were less likely to successfully complete the simulated patient-care scenario. An inhibition of the vagal activity was noted during the patient-care simulation among individuals identified with PTSD. No link was observed between physical health conditions (CVD, MSD) and simulated patient-care performance. Overall, paramedics who passed the patient-care simulation presented higher vagal activity during the patient assessment.

CONCLUSIONS: This research suggests that the presence of self-reported elevated symptoms of PTSD negatively impacts paramedics' performance during a stressful work task simulation. Therefore, to help paramedics maintain optimal performance, it may be important to ensure that paramedics have access to appropriate resources to monitor and improve their psychosocial health. Future studies should investigate more complex work tasks with larger sample sizes and more complex simulations.

\section{Background}

Paramedics' duties are characterized as highly demanding which can have a negative influence on workers' health status. It was documented that the demands of paramedics' duty represent a key factor influencing the workers' health status over both the short [1-4] and long term [5-10]. More precisely, organizational, physical and psychosocial work-related demands were identified as catalysts causing or accelerating the deterioration of health status among paramedics [1-4]. However, it is only recently that research has explored the potential links between the influence of health status on job performance.

Models relating work-related demands and health status have been published over the years (e.g. Job Demand-Control model, Job Demand-Control-Social model, Pearlin's Stress Process model, Job Demands-Resources model) [11-14]. Only a few models have theorized the impact of health status on occupational performance. The Job Demands-Resources model (JDR) [14] appears most appropriate in understanding the link of how job demands influence workers' health status, and consequently the link between health impairment and diminished job performance. For a detailed explanation of JDR model the reader is referred to Bakker and Demerouti [14]. JDR model has been developed in a work-related approach, and established an important link between "demands", "strain" and "performance". Bakker and Demerouti, considered that high job "demands" might have a negative impact on health workers. The term "strain" refers to health impairment (e.g. fatigue, depression, anxiety, health complaints), which in turn increases the job "demands" over time [14]. As such, health impairments represent a "strain" that might impair job "performance" [14]. For example, organizational demands (e.g. overnight duty, rotating schedules, irregular work hours) can cause fatigue and sleepiness among 
paramedics. Bentley et Levine [15], documented that twenty-five percent of paramedics reported difficulty remembering protocols during a patient-care intervention, because of fatigue and sleepiness. Patterson et al. [16] identified that odds of perceived compromised safety were approximatively five times higher among fatigued paramedics when compared to non-fatigued paramedics. Pyper \& Paterson [17] suggest that safety issues may include: errors with drug calculations and administration, poor concentration and impaired decision making; which would contribute to adverse safety outcomes for patients and paramedics [15-17].

Psychosocial demands are an important concern for paramedics since they must frequently perform their duty under stressful conditions [18]. Time pressure, multiple and frequent traumatic event exposures, responsibility for patient life, progression of patient condition have been associated with elevated psychosocial demand [19]. High psychosocial demand can result in elevated risk of psychosocial disorders such as post-traumatic stress disorders (PTSD), generalized anxiety disorders (GAD), depression, eating disorders as well as drug and alcohol addiction $[7,19]$. A study from Regehr and LeBlanc [20] documented the influence of PTSD symptoms severity on the occupational performance among four groups of emergency workers (i.e. paramedics $(n=22)$, police recruits $(n=84)$, dispatchers $(n=113)$ and child protection workers $(n=96)$ ). Regehr and LeBlanc used distinctive and stressful simulation for each profession. Regehr and LeBlanc [20] observed that the occupational performance was not associated with PTSD among paramedics and police recruits. In contrast, dispatchers and child protection workers showed a decrease in work-related performance. More specifically, dispatchers had worse and longer complex chart task, and child protection workers were less able to find a child at risk during the simulation. To explain their results, Regehr and LeBlanc [20] suggested that the stress level during the simulations might be too low, and insufficient to observe the influence of PTSD among paramedics and police recruits, but sufficient for the two other groups. In other words, the relationship between severity of PTSD symptoms and workrelated performance impairment might be related to the level of stress exposure. Additionally, the level of stress exposure also impairs the occupational performance of paramedics. LeBlanc's team [21, 22] have observed that drug calculation and memory recall (reporting information or action after an event) were impaired when paramedics experienced stressful patient-care simulation. Overall the relationship between high work-related demands and health-impairment is well-known in the paramedic literature, however the link between health-impairment and job performance seems complex and needs further investigation.

JDR model provides a conceptual framework that overviews the influence between work-related- "demands, "health status and job performance, without understanding of the underlying mechanisms. Vagal models (e.g. polyvagal theory, neurovisceral integration model) [23-28] from the neuroscience field of research provided a justification. Instead of comparing models, the current paper focus on their common points and generalized them to an occupational context. These models are built around the brain-heart relationship via autonomic nervous system modulation, more precisely through the monitoring of vagus nerve activity. The vagus nerve is the main nerve of the parasympathetic nervous system and its activity is identified as vagal tone. The vagal tone could be monitoring efficiently by the Heart Rate Variability (HRV) and its measure is related to emotional state, cognitive performance and health status [29-31]. These models show that a higher vagal tone, reflected by high HRV, represents better emotional self-regulation, executive functioning (e.g. reasoning, memory, attention) and health status. Inversely a lower vagal tone, reflected by low HRV has been associated to a poor emotional self-regulation (e.g. rigid, fear, treat, hypervigilance), a decline of executive functions and health impairments [29-32].

More precisely, several health impairments such as pain, inflammation, fatigue, diseases (e.g. CVD, diabetes, hypertension, obesity), disorders (PTSD, GAD, MSD) and cancers, have been reported to impair the vagal function by decreasing the vagal tone. This low tonic activity is also related to prefrontal cortex inhibition (low executive functions, lack of attention, working memory impairment) as well as an amygdala hyperactivity (increasing threat and fear perception, hypervigilance). By contrast, healthy vagal function has been related to better prefrontal control over an inhibition of amygdala function, resulting in a better adaptation to stressful situations [27, 29-33]. For example, it was

Page $3 / 23$ 
observed by Hansen et al. [34] among a cohort of sixty-five military navy sailors, divided into low HRV and high HRV groups, that the group with low HRV had worse performance to cognitive tasks (i.e. lower true positive responses and slower reaction time to the CalCAP test (a continuous performance task); higher false positive responses to the WMT (a working memory task) test). Even though the authors did not investigate the potential causes of that "low HRV group" (e.g. PTSD, anxiety, CVD, low level of physical fitness), the findings of Hansen et al. [34] study related individuals with a low vagal tone to have taxed cognitive functions. Individuals with health impairments have an elevated risk to have lower vagal tone and thus have lower HRV values than their "healthier" counter parts $[29,30]$ as well as individuals with high tone ("healthy") performed complex cognitive tasks involving executive functions better than those with lower HRV [27, $34,35]$.

It is known that cognitive functions are essential in paramedic duties to performed adequate patient-care. Paramedics must assess the patient condition, be aware of the safety issues, makes decisions based on evidence, provide adequate cares as well as demonstrates clear and concise communication abilities, which are all dependant on optimal cognitive functional workers. Consequently, it is reasonable to assume that paramedics with health impairments may experience a negative impact on the patient-care intervention, resulting in inferior quality of care or an unfortunate "adverse event". An adverse event "[...] is a harmful or potentially harmful event occurring during the continuum of EMS care that is potentially preventable and thus independent of the progression of the patient's condition" [36].

Nevertheless, the majority of the literature that has studied the influence of health impairments or low vagal tone on cognitive functions (e.g. executive functions, working memory, attention, flexibility) have used single health measures. Only a few studies (and work-related ones) have used occupational simulations. In order to capture the outcomes of health impairments, the current project selected the occupational simulation as methodological approach. Therefore, it stands to reason that paramedics health impairments could alter their ability to perform a stressful patient-care scenario. The aim of the project was to describe the performance to stressful patient-care simulated scenario of experienced paramedics with elevated risk of health impairment (CVD, MSD, PTSD, GAD). Furthermore, HRV was collected during the patient-care intervention in order to document vagal tone. It was anticipated that a higher proportion of individuals identified with elevated risk of health impairments would perform the patient-care simulation poorly and would demonstrate a lower vagal tone.

\section{Methods}

\section{Design}

A quasi-experimental design was used to explore the influence of health status on the vagal tone and on patient care simulation performance. This study received institutional research ethics board approval.

\section{Participants}

In collaboration with Ambulance New Brunswick (ANB), recruitment emails were sent out across the province of New Brunswick (NB, Canada). Twenty-five NB paramedics responded positively to participate. Four participants left the study during the data collection indicating scheduling conflicts. In addition, two were excluded from the analysis, due to recording problems during the data collection (video and task simulation files were not recorded properly). Overall nineteen paramedics, including six women and thirteen men aged $38.2 \pm 8.6$ (mean \pm standard deviation) years old with an average of $15.0 \pm 8.7$ years of paramedic experience, participated to this study.

\section{Procedures}


All testing took place in the University's laboratory. All participants were on their day off and were asked to have a full night of sleep in order to be rested prior to participating in this study. Upon arrival, each participant was briefed on experimental procedures. All participants read and signed a university research ethics committee approved informed consent. A demographic questionnaire (age, years of experience, sex) was administered to each participant. Afterwards, two assessments were performed: i) health measurements; and ii) simulated patient-care intervention.

The health measurements were based on a previous study by our research team [37], where health impairments were assessed among this cohort of experienced paramedics. The methodology used self-reported questionnaires and physical tests in order to reduce mono-measure bias, by combining at least two positive health measurements per health impairment. Health measurements are detailed in the next section.

Before the patient-care simulation started, the participants were familiarized with the simulation (patient simulator characteristics, room and equipment). After that, the participants remained seated comfortably on a chair, in a quiet and dimly lit room for a 5-minute baseline recording. Following the baseline period, participants were briefed about the history and the information of their fictitious patient (context and medical conditions of patient simulator). The clinical simulation occurred on a patient simulator located in $4 \mathrm{~m}^{2}$ room.

The simulation started when the participant entered the room. During the simulation, the participant was alone with the patient simulator. Therefore, there was no possibility of communication with their partner or dispatcher on the radio. Close to the patient simulator were three bags typically used by Ambulance New Brunswick paramedics (airway, cardiac monitor-defibrillator and medication). This ten-minute patient-care simulation was developed by a paramedic instructor in order to challenge paramedics. The simulation sequence was:

- minute 0 to 2: unconscious, breathing difficulty, high blood pressure, high heart rate, low oxygen saturation

- minute 2 to 3 : deterioration of the patient until to ventricular fibrillation

- minute 3 to 10: at this point if the participant does not provide adequate care, the patient will deteriorate until the patient dies after 7 minutes. If the participant provides the minimal care (which is defibrillation and CPR), the patient will stay unconscious but stable with irregular heartbeat. After 10-minutes, the scenario is stopped.

\section{Apparatus}

Electrocardiogram (ECG): Prior to the health measurements and the patient-care simulation, a 3-lead electrocardiogram (ECG) was placed on the participants. The electrode placement used LEAD II configuration according to Einthoven's triangle [38]. The heart signals were recorded using the Bio Amp unit (FE132) and an eight channel PowerLab unit (PL3508) (AdInstruments, USA) and LabChart software (version 7, Adlnstruments, USA). The ECG signal data collected were conditioned (i.e. 1 to $45 \mathrm{~Hz}$ band pass filter and normalized) using LabChart software (i.e. LabChart software version 7, Adlnstruments, USA) before calculation. The ECG signal was collected to obtain heart electrical activity during the YMCA step test (cardiovascular fitness level), the baseline period and patient-care simulation. The baseline values were used to assess the cardiovascular health of the participant (i.e. if they represent an elevated risk to develop CVD) as well as to measure the tonic vagal activity, and also measure the phasic vagal activity during the patient-care simulation in order to document the reactivity (vagal tone difference between patient-care simulation and baseline period).

\section{Health measurement tools}

\section{Questionnaires}


Self-reported health problem diagnosis. Self-reported surveys were used to obtain self-reported symptoms related to musculoskeletal disorders (MSD), cardiovascular diseases (CVD), post-traumatic stress disorders (PTSD) or generalized anxiety disorders (GAD).

Nordic questionnaire (NQ). NQ is a self-report validated tool measuring the history of MSD in the last 12 months and its occupational impact [39-41].

Civilian version of PTSD check list (PCL-C). PCL-C is a self-administered questionnaire for screening symptoms of PTSD in seventeen items that correspond to the symptoms of PTSD $[42,43]$. The National center of PTSD of US Department of Veterans' Affairs, suggested "36" as the lowest normative cut-off point for specialized medical clinics like paramedics. The PCL-C questionnaire is a valid and a reliable tool (Cronbach a-value $=0.94$; ICC r-value $=0.96)[42,43]$.

22-item Responses to stressful experiences scale (RSES-22). RSES-22 is a self-reported questionnaire measuring the level of resiliency. Low level of resiliency is associates to the severity of PTSD symptoms [44]. The score " 0 to 49" is associated to understand better low level of resilience [44]. The RSES-22 has been shown to be valid and reliable (Cronbach a-value $=0.91-0.93 ;$ ICC r-value $=0.87)$ [44]

13-item Sense of coherence (SOC-13). The SOC-13 is a self-reported questionnaire used to measure sense of coherence. Low sense of coherence is associated negatively to the severity of PTSD symptoms [45-49]. Ibrahim et al. [49] indicated that the score " 0 to 49 " is categorized as a low sense of coherence. The SOC-13 is a valid and reliable questionnaire (Cronbach a-value $=0.70-0.92 ;$ ICC r-value $=0.69-0.78)$ [45-48].

Generalized Anxiety Disorders (GAD-7). GAD-7 is a self-report tool assessing the severity of anxiety disorders with seven items. [50] demonstrated a strong validity and reliability for identifying anxiety (Cronbach a-value $=0.92$; ICC r-value = 0.83), which has been cited one of the most common psychosocial illnesses. GAD-7 provides a global score " 0 to 21 ", where value superior to nine is associated with anxiety disorders [51].

\section{Physical measurements}

Functional Movement Screen $\left(\underline{\mathrm{FMS}}^{\mathrm{Tw}}\right)$. Participants performed a FMS consisting of a series of seven movements as developed by Cook et al. [52]. The summed FMS score can range from " 0 to 21" [52-54]. A systematic review and metaanalysis found that FMS has excellent inter-rater and intra-rater reliability, including a pass/fail cut-off of 14 points being valid in predicting a higher risk of injury [55].

YMCA step test. The YMCA step test is a submaximal cardiovascular fitness test for individuals with a low exercise capacity or at risk of CVD [56]. This step-test is a 3-min single-stage test, which is used to predict fitness levels using the number of heart beats following the first minute of recovery. Heart rate was continuously monitored by ECG. Following exercise, participants were asked to sit quietly (without moving) for 1 minute. Beutner et al. [56] and Kasch et al. [57], have shown the YMCA step-test as a strong predictor of $\mathrm{VO}^{2} \max (r$-value $=0.83$ ). It was well-documented that a low level of cardiovascular fitness is associate with an elevated risk of mortality from CVD [58,59].

\section{Patient-care simulation}

Patient simulator: The "Kelly" Advanced Life Support (ALS) manikin (Laerdal Medical, ON, Canada) was used for this project. Kelly manikin is used for paramedics training. It can reproduce many signs and symptoms similar to a real patient and the paramedic can practice many invasive medical interventions on it, such as needle puncture, chess compression, intubation, insufflation, and defibrillation. Also, the patient simulator was connected wirelessly to an electronic tablet interface (SimPad; i.e. touchscreen patient' monitor from Laerdal Medical, ON, Canada). The SimPad 
records information of the patient simulator state, and the medical intervention from the paramedic. For example, the system detects and records chest compression, ventilation, head tilt, or if the paramedic has checked the carotid pulse. The simulation was programmed by an ANB paramedic instructor.

Video camera: One webcam (QuickCam Pro for notebook, Logitech, Switzerland) was installed on the ceiling of the room for recording (transverse view) the clinical simulation. The resolution and the frequency of video recording were $640 \times 360$ pixels and 15 images per second (Hertz).

Patient-care assessment tool: A posteriori patient-care intervention assessment was performed by an experienced paramedic instructor from ANB. The instructor evaluated the patient-care simulation using the videos recorded from the webcam and the SimPad data. The instructor based the evaluation on the provincial standard of New Brunswick. Five components were assessed: 1) patient assessment, 2) situational awareness, 3) decision making, 4) technical skill, 5) integration (detailed components are presented in Appendix A). Each component was assessed on a scale of one to six points, where 1 is "Performance caused harm to the patient"; 2 is "Performance indicated cause for concern and had potential to cause harm to the patient"; 3 is "Performance did not meet NB standards"; 4 is "Performance was satisfactory and met NB standards"; 5 is "Performance exceeds some NB standards"; and 6 is "Performance exceeds most NB standards".

\section{Outcomes}

\section{Health impairments}

Based on Tremblay et al. [37] participants were considered to have a health condition if they had two positive measures. Possible combinations of positive measures were: i) individual had self-reported diagnosis of adverse health impairments that should be confirmed by another health measurement or, ii) individual had at least two health measurements obtained by questionnaire and/or physical measure.

Elevated risk to develop future musculoskeletal disorders (MSD). Participants were considered as having elevated risk to develop MSD if they:

- self-reported being diagnosed with MSD $\underline{\text { AND }}$ had been positively screened with the NQ (work-related history of MSD in the last 12 month) $\underline{\text { OR }}$ with the FMS (scored below the cut-off point of fourteen) [55].

OR

- did not reported MSD diagnosis, but the participant had been positively screened with NQ $\underline{\text { AND }}$

Elevated risk to develop future cardiovascular diseases $(\underline{C V D})$. The baseline period was used as health measure in order to evaluate the risk of developing cardiovascular diseases (CVD). When the standard deviation time between inter-beatinterval (from HRV calculation) was lower than 50 milliseconds (SDNN50), the participant was considered to have low HRV. Low HRV represents an increased risk of cardiovascular morbidity and mortality $[60,61]$. Therefore, participants were identified as having elevated risk of developing CVD if they:

- self-reported being diagnosed with CVD $\underline{\text { AND }}$ had scored "below the average" on the YMCA step test [56] OR SDNN50 [60].

$\underline{\mathrm{OR}}$

- did not reported CVD diagnosis but the participant had been positively screened with YMCA AND SDNN50. 
Elevated symptoms of post-traumatic stress disorders (PTSD). Participants were considered to suffer of elevated symptoms of PTSD if they:

- self-reported being diagnosed with PTSD $\underline{\text { AND }}$ had been positively screened for PCL-C (scored higher than 36) [42,43] $\underline{\mathrm{OR}}$ had scored a low level of resilience (0 to 49) at the RSES-22 [44]; $\underline{\mathrm{OR}}$, had scored a low level of sense of coherence (0 to 55$)$ at the SOC-13 [49].

\section{$\underline{\mathrm{OR}}$}

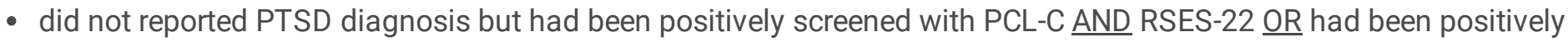
screened with PCL-C AND SOC-13.

Elevated symptoms of generalized anxiety disorders (GAD). Participants were considered to suffer of elevated symptoms of GAD if they self-reported being diagnosed with GAD $\underline{\text { AND }}$ had scored nine and higher at GAD-7.

\section{Vagal activity}

The vagal activity was divided into two components: i) baseline and patient-care simulation. The baseline is the resting HRV value, known as tonic vagal value. The patient care simulation was also divided into two parts: 1) the patient assessment and ii) the intervention. The patient assessment was considered cognitively demanding, compared to the patient-care intervention which was expected to involve the participant executing a CPR maneuver, which is considered a moderate to high physical demand [62,63]. The participant was considered in the "intervention", when she/he started the CPR maneuver. The phasic vagal activity referred to the HRV reactivity while the patient-care simulations parts were performed. For this study, phasic vagal was calculated as a ratio from the difference between the HRV value during to the patient-care simulation and HRV value during the baseline period. For instance, a value of "- 0.5 " means that the patientcare simulation elicited $50 \%$ more activity than the physiological baseline period. The higher the ratio, the more reactivity was considered.

Poincaré plot analysis are used to obtained HRV values, and describe the vagal activity $[29,64,65]$. SD1 (standard deviation of points perpendicular to the line-of-equality) measured the short-term HRV and is associated with the influence of parasympathetic activity. Moreover, it is similar to RMSSD (root mean square of successive IBI differences) and associated positively to HF power (power of high-frequency band: $0.15-0.4 \mathrm{~Hz}$ ) $[29,64,65]$.

\section{Patient-care simulation performance}

To succeeded the patient-care simulation performance, the participants needed to obtain at least 3 points on a scale of 6 , on each five components. A score lower than 3 indicated a potential to cause harm to the patient or resulting in an adverse event, that could lead to the death of the patient.

\section{Descriptive analysis}

Descriptive statistics (frequency, percentage, mean $\pm 95 \%$ confidence interval) were used to present the participants health impairments (MSD, CVD, PTSD, GAD), simulated patient-care intervention performance as well as the vagal activity. Microsoft Excel version 1808 (Microsoft Corporation, USA) was used to conduct statistical analysis.

\section{Results}


Thirty-seven percent of participants presented an elevated risk for MSD, 37\% of participants had an elevated risk to develop CVD and $16 \%$ of participants had elevated symptoms of PTSD. No individual was identified with elevated symptoms of GAD. Table 1 summarizes for each participant results on each health measure (MSD, CVD, PTSD, GAD).

The tables 1 and 2 show that $53 \%$ of participants had success in the patient-care simulation, and $60 \%$ of them had elevated risk of health impairments (i.e. MSD, CVD). In contrast, $47 \%$ of participants failed the patient-care simulation, and $67 \%$ had elevated risk of health conditions (i.e. MSD, CVD, PTSD). Also, 100 percent of the participants who had elevated symptoms of PTSD failed the patient-care simulation. In Table 2, show that participants with the best performance in patient-care (i.e. $23,24,25$ ), also did not have an identified health impairment.

The Fig. 1 presents the tonic activity (baseline), where it was observed that the participants who were successful in the patient-care simulation had lower tonic values than their counterparts who failed the patient-care simulation (All passed $20.01 \pm 5.84 \mathrm{~ms}$. vs. failed $27.06 \pm 16.62 \mathrm{~ms}$.; Healthy passed $26.28 \pm 4.47 \mathrm{~ms}$. vs. failed $42.55 \pm 25.02 \mathrm{~ms}$.; MSD Passed $11.42 \pm 4.73 \mathrm{~ms}$. vs. failed $22.49 \pm 12.00 \mathrm{~ms}$.); except for participants identified with an elevated risk of CVD that was inverted (14.39 $\pm 6.00 \mathrm{~ms}$. vs. $8.97 \pm 2.07 \mathrm{~ms}$.). In addition, the Fig. 1 show less variability among the participants who had succeed than the participants who failed.

Regarding the patient-care simulation, all participants who had succeeded in the patient-care simulation had higher phasic activity (reactivity) during the assessment period than the participants who failed the simulation (Fig. 2). However, when comparing healthy participants (passed and failed combined), they have similar phasic activity (passed $-0.73 \pm$ 0.15 ; failed $-0.68 \pm 0.06$ ), which is higher than participants identified with health impairments (CVD, MSD, PTSD) (CVD passed $-0.44 \pm 0.29$ vs. CVD failed $0.69 \pm 0.22$; MSD passed $-0.32 \pm 0.29$ vs. MSD failed $-0.17 \pm 0.61$; PTSD failed 0.19 $\pm 0.60)$. In addition, participants who had failed the simulation and had elevated risk of CVD or elevated symptoms of PTSD show an inverted phasic activity during the assessment period (CVD failed $0.69 \pm 0.22$; PTSD failed $0.19 \pm 0.60$ ). Figure 2 shows less variability among the participants who had succeed than the participants who failed.

Figure 3 presents that during the intervention period all participants who had succeeded in patient-care simulation had a greater phasic activity when comparing with participants who failed the simulation $(-0.77 \pm 0.10$ vs. $-0,57 \pm 0.27$, respectively). Regardless if they succeeded or not in the simulation, healthy participants had similarly high phasic activity (passed $-0.83 \pm 0.04$; failed $-0,79 \pm 0.09$ ). In addition, participants had failed the simulation and had elevated risk of CVD demonstrated the lowest phasic activity during the intervention period $(-0.19 \pm 0.26)$. Figure 3 shows that there was less variability among the participants who had succeeded than the participants who failed.

\section{Discussion}

The simulated patient-care intervention was developed to be stressful and challenging for experienced paramedics, where the participants needed to assess the patient condition correctly and provide appropriate primary medical care. It was not anticipated that almost half of the experienced paramedics' cohort would fail the simulation. The authors of the current paper hypothesize that the unexpected fail rate might be caused by the influence of the evaluation itself. More precisely, it was documented that participants who are observed are more stressed and thus would change their behaviours (voluntary or involuntary) and have an increase of their blood pressure [66].

Furthermore, LeBlanc's team [21, 22] have documented that paramedics who experienced stressful and challenging patient-care simulation are inclined to have impaired work abilities (e.g. calculation, memory recall). Considering the fact that the participants who failed the patient-care simulation did not have a specific weakness (most of all participants who failed have one point between the highest and lowest score; see Table 2), but an overall influence of the stress. Therefore, it did not appear that the current cohort had competency or skills issues, but rather they seem to be more influenced globally by the stress caused by the evaluation of patient-care simulation performance.

Page $9 / 23$ 


\section{Health impairments}

Based on the JDR model, it was hypothesized that the presence of a health impairment would lead to decrement in occupational performance. The findings of this research partially confirm this existence of this link among paramedics. Bakker and Demerouti [14] modelized health impairment as "strain" that could potentially alter occupational performance. This was only partially the case. The difference in performance are measures between success and failure were small. Although more paramedics with elevated risk of CV and MSD did fail the patient-care simulation, it was not consistent for all participants with a health impairment. An interesting finding was that all participants identified with elevated symptoms of PTSD failed the patient-care simulation. Thus, it seems that only elevated symptoms of PTSD had a negative influence on the paramedics' ability to effectively perform prehospital emergency care.

Additionally, it was proposed by Regehr and LeBlanc [20] that among the paramedics, the relationship between occupational performance impairment and PTSD might be related to the level of stress exposure of the work-related simulation. Considering that all paramedics identified with elevated symptoms of PTSD who failed the patient-care simulation, it seems that the current study has triggered sufficient level of stress exposure.

It has been documented that PTSD plays a role in the reduction of cognitive performance efficiency, and more specifically of cognitive functions $[27,67,68]$. Therefore, it is reasonable that paramedics with elevated symptoms of PTSD may experience a negative impact on the patient-care intervention, resulting in inferior quality of care or an unfortunate adverse event [36]. However, this link seems not to be clear among the emergency workers, because the results of the current study seem to contradict the result of Leblanc et al.[69], who did not observe that first responders with elevated symptoms of PTSD perform differently during a stressful occupational simulation. LeBlanc et al. [69] compared two groups of police officers (high and low symptoms of PTSD) and they observed no significant difference between both groups during simulated emergency response. However, there are some methodological differences between this study and the current research. For example, the current study evaluated experienced participants compared to Leblanc's recruits (15.0 \pm 8.7 vs. $0.18 \pm 0.31$ years of experience), who were younger, and in better physical and psychosocial condition. LeBlanc's participants were fresh-out of the academy and had less exposure to chronic and major traumatic events in their professional life. It is also surprising that young individuals might suffer from severe PTSD symptoms. However, it was documented that younger age and higher fitness level (physical and mental) are associated positively to better cognitive performance performed and conversely, ageing and low level of physical fitness tend to reduce cognitive performance [70-72]. Regarding the second methodological aspect, the current study performed double-positive health screening compared to Leblanc's single method to identify the participants' symptoms. This aspect may have caused an inflation of individuals identified with high symptoms of PTSD, and therefore would not be able to discriminate the participants properly (high vs low symptoms).

Despite the fact that the current study did not observe the link between physical health impairments (CVD, MSD) and patient-care performance impairment, this does not mean that they don't have any effect. Considering that individuals identified with physical health impairments (CVD, MSD) underperform while occupational activities without stressful condition [73-75], it is reasonable to assume that they should have some impact when they perform in a stressful environment. Therefore, in the current study, only paramedics identified with PTSD have shown negative consequences on paramedics' occupational performance, the influence of other health impairments seems divided or mitigated. However further research is needed to identify the causes and its triggers, especially in order to provide a better understanding of the age, years of experience, level of exposure to chronic and major traumatic, stress level exposure.

\section{Vagal activity}


Neuroscience research has documented that individuals with a high tonic activity (vagal baseline at resting) are associated with better cognitive performance and adaptation to stressful environments [27,29-33]. By contrast, individuals who have low tonic activity show lower cognitive performance and they presented a lack of adaptation in stressful situations $[27,32,76]$. The results of this study suggest the opposite, where individuals who failed the patientcare simulation presented with higher tonic activity. A reason that might explain that difference, is based on the fact that most of cognitive performance assessed in the literature has been measured individually, where each variable is controlled and the groups of participants are homogenous. In contrast, the patient-care simulation is a complex task, but already known, as paramedics are trained in this manner. The within and between groups variability highlighted that the cohort was not homogenous, as most variables are difficult to control (e.g. age, year of experience, gender, education, incomes, health impairments, level of exposure to chronic and major traumatic, stress level exposition, perception). Considering that the current project has used a complex occupational simulation, the tonic activity did not appear to be related to the patient-care simulation among this cohort of experienced paramedics.

Regardless of the success of the patient-care simulation or the presence of health condition, the phasic activity (vagal reactivity to the patient-care simulation) revealed that the assessment segment was more cognitively demanding (due to evaluation of the situation and the patient), and the intervention segment was more physically demanding (due to the CPR maneuver). CPR maneuver is considered as moderate to high physically demanding task [62,63]. In addition, phasic activity appears more linked the occupational performance than the vagal activity among this cohort of experienced paramedics. Paramedics who successfully completed the patient-care simulation presented higher phasic activity during both segments (assessment, intervention). The participants identified with elevated risk of CVD and elevated symptoms of PTSD presented an inhibition of the vagal activity during the assessment segment of the simulation. Thus, it seems that low phasic activity and a performance impairment present some relationships during the more "cognitive" segment of the simulation, among experienced paramedics identified with elevated symptoms of PTSD. Furthermore, because of the wide variability during the assessment segment among participants with elevated PTSD symptoms, it is difficult to speculate on the causes of that difference. Gillie and Thayer [77] suggested that this individual difference might be caused by various cognitive control abilities and symptom severity, where individuals could re-experience intrusive memories and thoughts.

The work of Thayer's team [26-28] helps in understanding the link between PTSD and patient-care performance. Thayer et al. identified that the stress (cognitive, emotional, physical) as a cause a vagal inhibition resulting in a deactivation of the brain's prefrontal cortex, suggesting that the patient-care simulation might produce stress among paramedics who were already weakened by their psychosocial health condition (i.e. PTSD). Thayer et al. suggest also that emotional stress had more negative consequences than other stresses on an individual identified with psychosocial issues cognitive tasks $[27,28]$. Important cognitive skills are controlled by the prefrontal cortex. This area oversees the cognitive executive functions, such as staying focus, switching attention, remembering details, time and task management, problem-solving, multitasking, decision making, task execution based on experience and training $[27,67,68]$. Thus, cognitive executive functions are essentials for paramedics' duty such for patient-care interventions. Therefore, it might be plausible that experienced paramedics with PTSD could have experienced emotional stress caused by a simulated patient-care scenario, provoking thus an inhibition of vagal activity limiting their cognitive ability to perform an adequate patient-care assessment and its proper intervention. Consequently, this might be resulting in adverse events that could lead to the death of the patient. However, further research is needed to confirm this hypothesis.

\section{Practical implications}

The current study has shown that paramedics identified with elevated symptoms of PTSD failed the patient-care simulation task, and this was coupled with a unique vagal activity during the assessment segment. Considering, the high rate of PTSD among the paramedic population [5], the need for professional associations, paramedic schools and EMS 
agencies should pay increased attention and provide additional resources regarding personal management and awareness on the potential impact negative impacts to patient care.

Additionally, as military, special forces or airline pilots, paramedics must be trained frequently and prepared for the "worst", in order to provide them the tools on how to deal with and cope with the physical and mental stress if these difficult situations. It has been documented, that simulation training performed in stressful conditions improved clinical performance and non-technical skills among health professional [78,79]. The second type of training that has been identified with beneficial influence is fitness training. Frequent aerobic and resistance exercises were well known to improve and maintain good health status but also increase the vagal activity in response to physical and mental stress [80]. It has been observed that physical activity had beneficial effects on PTSD symptoms [81] and that individuals who suffered of PTSD and regularly practice physical activity showed better cognitive performance [82].

\section{Future research}

Patterson et al. [83] noted that "the impact of patient workload, intensity or duration patient-care" remains limited, suggesting that " future studies are needed that capture detailed measures of workload". Despite the increase in research over the last decade, more investigation is needed, to better understand the impacts of psychosocial health on paramedics' occupational performance. Similar to Coffey et al. [84], where they quantified the physical demands of paramedics across Canada, quantifying and describing psychosocial demands of the paramedics' duty is important. Establishing a complete list of standards, not only physical, but also psychosocial, of Canadian paramedics' duty is needed, as suggested by Paramedic Chiefs of Canada (PCC)[85], Canadian House of Commons [86] and Canadian Standards Association (CSA) group [87].

\section{Study limitations}

Volunteer recruitment was difficult for this project. Over one-thousand emails were sent out to all New Brunswick paramedics. From those emails, only twenty-five paramedics responded positively. This number of volunteers limited the sample size of this project. One hypothesis that might help to explain this lack of participation, was identified as the assessment of health status and occupational performance. Some paramedics mentioned their fear of being branded as "not fit for duty" or "not enough competent to work" and therefore might be at risk of losing their job. Even if it was stated that the employer would never be informed of such results. Consequently, it is understood that the participation in this study is a limited sample and it would have been ideal to have a stronger representation to generalize the results.

Simulation allow us to repeated and controlled some of the experimental conditions, the vagal activity obtained from this cohort of experienced paramedics might be limited by the simulation. It might be interesting to compare and validate our results with a "on the field" study.

\section{Conclusions}

This exploratory research observed that PTSD was related to negative patient-care performance among experienced paramedics. It quantified the physiological activity during a simulated occupational task performed under stress condition (divided into two periods: assessment and intervention including CPR maneuver). As observed in the literature, individuals who successfully passed the patient-care task had higher vagal activity during the patient assessment. During the same period of the simulation, paramedics with elevated symptoms of PTSD did not show the same tendencies, instead presenting a wide variability of activity. Also, compared with other participants, paramedics with elevated symptoms of PTSD while performing the patient-care simulation, presented an unbalance activity due to a reduction of vagal activity. Emotional stress was suggested to be triggered by patient-care, causing an inhibition of vagal activity 
restraining their cognitive skills translated potentially by substandard quality of care and adverse event. Considering the potential impacts of PTSD, we suggest that professional associations, paramedic schools and EMS should consider to ensure that paramedics have access to appropriate resources to monitor and improve the psychosocial health among paramedics. More research is needed to provide a better understanding of the influence psychosocial health status on paramedics.

\section{Declarations}

\section{Ethical approval and consent to participate}

The research protocol was submitted and approved by the Ethical Committee of the Université de Moncton (approval number CER\#1213-059). Written informed consent was obtained from all study participants.

\section{Consent for publication}

Not applicable.

\section{Availability of data and materials}

Please contact Mathieu Tremblay for data requests.

\section{Competing interests}

The authors declare that they have no competing interests.

\section{Funding}

Not applicable.

\section{Authors' contributions}

MT, WA, SF, EB, MJ conceived the study; MT, WA, EB, MJ supervised the data collection; MT, WA, SF, EB, MJ provided statistical advice on study, design and analyzed the data; MT drafted the manuscript and all authors contributed substantially to its revision. All authors have read and approved the manuscript.

\section{Acknowledgments}

Not applicable.

\section{Abbreviations}

ANB: Ambulance New Brunswick;

CPR: Cardiopulmonary Resuscitation

CVD: Cardiovascular Diseases

Diag: Self-reported diagnosis

ECG: Electrocardiogram

EMS: Emergency Medical Services 
FMS: Functional Movement Screen (physical measurement)

GAD: Generalized Anxiety Disorders

GAD-7: 7-item Generalized Anxiety Disorders (questionnaire)

HRV: Heart Rate Variability

ms.: Milliseconds

NB: Province of New Brunswick (Canada)

NQ: Nordic questionnaire

PCL-C: Civilian version of PTSD check list (questionnaire)

PTSD: Post-Traumatic Stress Disorders

RSES-22: 22-item Responses to stressful experiences scale (questionnaire)

SDNN50: Standard deviation time between inter-beat-interval is lower than 50 milliseconds (from HRV calculation)

SOC-13: 13-item Sense of coherence (questionnaire)

YMCA: 3-min step test

\section{References}

1. Reichard AA, Jackson LL. Occupational injuries among emergency responders. Am J Ind Med. 2010 Jan;53(1):1-11.

2. Van der Ploeg E, Kleber RJ. Acute and chronic job stressors among ambulance personnel: predictors of health symptoms. Occup Environ Med. 2003 Jun;60 Suppl 1:i40-46.

3. Maguire BJ, Smith S. Injuries and fatalities among emergency medical technicians and paramedics in the United States. Prehospital Disaster Med. 2013 Aug;28(4):376-82.

4. Maguire BJ, O’Meara PF, Brightwell RF, O’Neill BJ, Fitzgerald GJ. Occupational injury risk among Australian paramedics: an analysis of national data. Med J Aust. 2014 May 5;200(8):477-80.

5. Carleton RN, Afifi TO, Turner S, Taillieu T, Duranceau S, LeBouthillier DM, et al. Mental Disorder Symptoms among Public Safety Personnel in Canada. Can J Psychiatry. 2018 Jan 1;63(1):54-64.

6. Dropkin J, Moline J, Power PM, Kim H. A qualitative study of health problems, risk factors, and prevention among Emergency Medical Service workers. Work Read Mass. 2015;52(4):935-51.

7. Hansen CD, Rasmussen K, Kyed M, Nielsen KJ, Andersen JH. Physical and psychosocial work environment factors and their association with health outcomes in Danish ambulance personnel - a cross-sectional study. BMC Public Health. 2012 Jul 23;12(1):534.

8. Halpern J, Maunder RG, Schwartz B, Gurevich M. The critical incident inventory: characteristics of incidents which affect emergency medical technicians and paramedics. BMC Emerg Med. 2012;12:10.

9. Hegg-Deloye S, Brassard P, Prairie J, Larouche D, Jauvin N, Poirier P, et al. Prevalence of risk factors for cardiovascular disease in paramedics. Int Arch Occup Environ Health. 2015;1-8.

10. Hegg-Deloye S, Brassard P, Jauvin N, Prairie J, Larouche D, Poirier P, et al. Current state of knowledge of posttraumatic stress, sleeping problems, obesity and cardiovascular disease in paramedics. Emerg Med J EMJ. 2014; 
11. Karasek R, Baker D, Marxer F, Ahlbom A, Theorell T. Job decision latitude, job demands, and cardiovascular disease: a prospective study of Swedish men. Am J Public Health. 1981 Jul;71(7):694-705.

12. Pearlin LI. The sociological study of stress. J Health Soc Behav. 1989 Sep;30(3):241-56.

13. Johnson JV, Hall EM, Theorell T. Combined effects of job strain and social isolation on cardiovascular disease morbidity and mortality in a random sample of the Swedish male working population. Scand J Work Environ Health. 1989;15(4):271-9.

14. Bakker AB, Demerouti E. Job demands-resources theory: Taking stock and looking forward. J Occup Health Psychol. 2017;22(3):273-85.

15. Bentley MA, Levine R. A National Assessment of the Health and Safety of Emergency Medical Services Professionals. Prehospital Disaster Med. 2016 Dec;31(S1):S96-104.

16. Patterson PD, Weaver MD, Frank RC, Warner CW, Martin-Gill C, Guyette FX, et al. Association between poor sleep, fatigue, and safety outcomes in Emergency Medical Services providers. Prehospital Emerg Care Off J Natl Assoc EMS Physicians Natl Assoc State EMS Dir. 2012 Jan;16(1):86.

17. Pyper Z, Paterson JL. Fatigue and mental health in Australian rural and regional ambulance personnel. Emerg Med Australas EMA. 2016 Feb;28(1):62-6.

18. Dutton LM, Smolensky MH, Lorimor R, Leach CS. Psychological stress levels in paramedics. Emerg Med Serv. 1978 Oct;7(5):88, 90-4, 113.

19. Aasa U, Brulin C, Ängquist K, Barnekow-Bergkvist M. Work-related psychosocial factors, worry about work conditions and health complaints among female and male ambulance personnel. Scand J Caring Sci. 2005 Sep;19(3):251-8.

20. Regehr C, LeBlanc VR. PTSD, Acute Stress, Performance and Decision-Making in Emergency Service Workers. J Am Acad Psychiatry Law. 2017 Jun;45(2):184-92.

21. LeBlanc VR, MacDonald RD, McArthur B, King K, Lepine T. Paramedic performance in calculating drug dosages following stressful scenarios in a human patient simulator. Prehospital Emerg Care Off J Natl Assoc EMS Physicians Natl Assoc State EMS Dir. 2005 Dec;9(4):439-44.

22. Leblanc VR, Regehr C, Tavares W, Scott AK, Macdonald R, King K. The impact of stress on paramedic performance during simulated critical events. Prehospital Disaster Med. 2012 Aug;27(4):369-74.

23. Porges SW. Orienting in a defensive world: mammalian modifications of our evolutionary heritage. A Polyvagal Theory. Psychophysiology. 1995 Jul;32(4):301-18.

24. Kolacz J, Porges SW. Corrigendum: Chronic Diffuse Pain and Functional Gastrointestinal Disorders After Traumatic Stress: Pathophysiology Through a Polyvagal Perspective. Front Med. 2018;5:229.

25. Williamson JB, Porges EC, Lamb DG, Porges SW. Maladaptive autonomic regulation in PTSD accelerates physiological aging. Front Psychol. 2014;5:1571.

26. Thayer JF, Lane RD. A model of neurovisceral integration in emotion regulation and dysregulation. J Affect Disord. 2000 Dec 2;61(3):201-16.

27. Thayer JF, Hansen AL, Saus-Rose E, Johnsen BH. Heart rate variability, prefrontal neural function, and cognitive performance: the neurovisceral integration perspective on self-regulation, adaptation, and health. Ann Behav Med Publ Soc Behav Med. 2009 Apr;37(2):141-53.

28. Thayer JF, Åhs F, Fredrikson M, Sollers JJ, Wager TD. A meta-analysis of heart rate variability and neuroimaging studies: Implications for heart rate variability as a marker of stress and health. Neurosci Biobehav Rev. 2012 Feb 1;36(2):747-56.

29. Shaffer F, Ginsberg JP. An Overview of Heart Rate Variability Metrics and Norms. Front Public Health. 2017 Sep 28;5.

30. Shaffer F, McCraty R, Zerr CL. A healthy heart is not a metronome: an integrative review of the heart's anatomy and heart rate variability. Front Psychol. 2014;5. 
31. Laborde S, Mosley E, Mertgen A. A unifying conceptual framework of factors associated to cardiac vagal control. Heliyon. 2018 Dec 1;4(12):e01002.

32. Park G, Vasey MW, Van Bavel JJ, Thayer JF. When tonic cardiac vagal tone predicts changes in phasic vagal tone: The role of fear and perceptual load: Tonic and phasic cardiac activity under load. Psychophysiology. 2014 May;51(5):419-26.

33. Kemp AH, Koenig J, Thayer JF. From psychological moments to mortality: A multidisciplinary synthesis on heart rate variability spanning the continuum of time. Neurosci Biobehav Rev. 2017 Dec;83:547-67.

34. Hansen $\mathrm{AL}$, Johnsen $\mathrm{BH}$, Thayer JF. Relationship between heart rate variability and cognitive function during threat of shock. Anxiety Stress Coping. 2009 Jan;22(1):77-89.

35. Hansen AL, Johnsen BH, Thayer JF. Vagal influence on working memory and attention. Int J Psychophysiol Off $\mathrm{J}$ Int Organ Psychophysiol. 2003 Jun;48(3):263-74.

36. Patterson PD, Weaver MD, Abebe K, Martin-Gill C, Roth RN, Suyama J, et al. Identification of adverse events in ground transport emergency medical services. Am J Med Qual Off J Am Coll Med Qual. 2012 Apr;27(2):139-46.

37. Tremblay M, Albert WJ, Fischer SL, Beairsto E, Johnson MJ. Exploration of the health status of experienced New Brunswick paramedics. WORK. In press;(spring 2020).

38. Becker DE. Fundamentals of Electrocardiography Interpretation. Anesth Prog. 2006;53(2):53-64.

39. Kuorinka I, Jonsson B, Kilbom A, Vinterberg H, Biering-Sørensen F, Andersson G, et al. Standardised Nordic questionnaires for the analysis of musculoskeletal symptoms. Appl Ergon. 1987 Sep;18(3):233-7.

40. Crawford JO. The Nordic Musculoskeletal Questionnaire. Occup Med. 2007 Jun 1;57(4):300-1.

41. Dickinson CE, Campion K, Foster AF, Newman SJ, O'Rourke AM, Thomas PG. Questionnaire development: an examination of the Nordic Musculoskeletal questionnaire. Appl Ergon. 1992 Jun;23(3):197-201.

42. Blanchard EB, Jones-Alexander J, Buckley TC, Forneris CA. Psychometric properties of the PTSD Checklist (PCL). Behav Res Ther. 1996 Aug;34(8):669-73.

43. Wilkins KC, Lang AJ, Norman SB. Synthesis of the psychometric properties of the PTSD checklist (PCL) military, civilian, and specific versions. Depress Anxiety. 2011 Jul;28(7):596-606.

44. Johnson DC, Polusny MA, Erbes CR, King D, King L, Litz BT, et al. Development and initial validation of the Response to Stressful Experiences Scale. Mil Med. 2011 Feb;176(2):161-9.

45. Antonovsky A. The structure and properties of the sense of coherence scale. Soc Sci Med 1982. 1993 Mar;36(6):72533.

46. Eriksson M, Lindstrom B. Validity of Antonovsky's sense of coherence scale: a systematic review. J Epidemiol Community Health. 2005 Jun;59(6):460-6.

47. Eriksson M, Lindström B. Antonovsky's sense of coherence scale and the relation with health: a systematic review. J Epidemiol Community Health. 2006 May;60(5):376-81.

48. Eriksson M, Lindström B. Antonovsky's sense of coherence scale and its relation with quality of life: a systematic review. J Epidemiol Community Health. 2007 Nov;61(11):938-44.

49. Ibrahim SA, Scott FE, Cole DC, Shannon HS, Eyles J. Job strain and self-reported health among working women and men: an analysis of the 1994/5 Canadian National Population Health Survey. Women Health. 2001;33(1-2):105-24.

50. Spitzer RL, Kroenke K, Williams JBW, Löwe B. A brief measure for assessing generalized anxiety disorder: the GAD-7. Arch Intern Med. 2006 May 22;166(10):1092-7.

51. Swinson RP. The GAD-7 scale was accurate for diagnosing generalised anxiety disorder. Evid Based Med. 2006 Dec;11(6):184.

52. Cook G, Burton L, Hoogenboom B. Pre-Participation Screening: The Use of Fundamental Movements as an Assessment of Function - Part 1. North Am J Sports Phys Ther NAJSPT. 2006 May;1(2):62-72. 
53. Lisman P, O'Connor FG, Deuster PA, Knapik JJ. Functional movement screen and aerobic fitness predict injuries in military training. Med Sci Sports Exerc. 2013 Apr;45(4):636-43.

54. Perry FT, Koehle MS. Normative data for the functional movement screen in middle-aged adults. J Strength Cond Res. 2013 Feb;27(2):458-62.

55. Bonazza NA, Smuin D, Onks CA, Silvis ML, Dhawan A. Reliability, Validity, and Injury Predictive Value of the Functional Movement Screen: A Systematic Review and Meta-analysis. Am J Sports Med. 2016 Apr 29;

56. Beutner F, Ubrich R, Zachariae S, Engel C, Sandri M, Teren A, et al. Validation of a brief step-test protocol for estimation of peak oxygen uptake. Eur J Prev Cardiol. 2015 Apr;22(4):503-12.

57. Kasch FW, Phillips WH, Ross WD, Carter JE, Boyer JL. A comparison of maximal oxygen uptake by treadmill and steptest procedures. J Appl Physiol. 1966 Jul;21(4):1387-8.

58. Laukkanen JA, Rauramaa R, Salonen JT, Kurl S. The predictive value of cardiorespiratory fitness combined with coronary risk evaluation and the risk of cardiovascular and all-cause death. J Intern Med. 2007 Aug;262(2):263-72.

59. Gupta S, Rohatgi A, Ayers CR, Willis BL, Haskell WL, Khera A, et al. Cardiorespiratory Fitness and Classification of Risk of Cardiovascular Disease Mortality. Circulation. 2011 Apr 5;123(13):1377-83.

60. Kleiger RE, Stein PK, Bigger JT Jr. Heart rate variability: measurement and clinical utility. Ann Noninvasive Electrocardiol Off J Int Soc Holter Noninvasive Electrocardiol Inc. 2005 Jan;10(1):88-101.

61. Hillebrand S, Gast KB, de Mutsert R, Swenne CA, Jukema JW, Middeldorp S, et al. Heart rate variability and first cardiovascular event in populations without known cardiovascular disease: meta-analysis and dose-response metaregression. Europace. 2013 May;15(5):742-9.

62. Lucía A, de las Heras JF, Pérez M, Elvira JC, Carvajal A, Alvarez AJ, et al. The importance of physical fitness in the performance of adequate cardiopulmonary resuscitation. Chest. 1999 Jan;115(1):158-64.

63. Gamble RP, Stevens AB, McBrien H, Black A, Cran GW, Boreham CA. Physical fitness and occupational demands of the Belfast ambulance service. Br J Ind Med. 1991 Sep;48(9):592-6.

64. Hallman DM, Srinivasan D, Mathiassen SE. Short- and long-term reliability of heart rate variability indices during repetitive low-force work. Eur J Appl Physiol. 2015 Apr 1;115(4):803-12.

65. Karmakar CK, Khandoker AH, Voss A, Palaniswami M. Sensitivity of temporal heart rate variability in Poincaré plot to changes in parasympathetic nervous system activity. Biomed Eng OnLine. 2011 Mar 3;10:17.

66. Lantelme Pierre, Milon Hugues, Gharib Claude, Gayet Christian, Fortrat Jacques-Olivier. White Coat Effect and Reactivity to Stress. Hypertension. 1998 Apr 1;31(4):1021-9.

67. Aupperle RL, Melrose AJ, Stein MB, Paulus MP. Executive Function and PTSD: Disengaging from Trauma. Neuropharmacology. 2012 Feb;62(2):686-94.

68. Diamond A. Executive Functions. Annu Rev Psychol. 2013;64:135-68.

69. LeBlanc VR, Regehr C, Jelley RB, Barath I. Does posttraumatic stress disorder (PTSD) affect performance? J Nerv Ment Dis. 2007 Aug;195(8):701-4.

70. Hayes SM, Alosco ML, Hayes JP, Cadden M, Peterson KM, Allsup K, et al. Physical Activity Is Positively Associated with Episodic Memory in Aging. J Int Neuropsychol Soc JINS. 2015 Nov;21(10):780-90.

71. Ranchet M, Morgan JC, Akinwuntan AE, Devos H. Cognitive workload across the spectrum of cognitive impairments: A systematic review of physiological measures. Neurosci Biobehav Rev. 2017 Sep;80:516-37.

72. Dupuy O, Bosquet L, Fraser SA, Labelle V, Bherer L. Higher cardiovascular fitness level is associated to better cognitive dual-task performance in Master Athletes: Mediation by cardiac autonomic control. Brain Cogn. 2018 Aug;125:12734.

73. Gaudet J, Bélanger MF, Corriveau H, Mekary S, Hay D, Johnson MJ. Investigating the autonomic nervous system and cognitive functions as potential mediators of an association between cardiovascular disease and driving 
performance. Can J Physiol Pharmacol. 2013 May;91(5):346-52.

74. Moriarty O, McGuire BE, Finn DP. The effect of pain on cognitive function: a review of clinical and preclinical research. Prog Neurobiol. 2011 Mar;93(3):385-404.

75. Veldhuijzen DS, Kenemans JL, de Bruin CM, Olivier B, Volkerts ER. Pain and attention: attentional disruption or distraction? J Pain Off J Am Pain Soc. 2006 Jan;7(1):11-20.

76. Laborde S, Mosley E, Thayer JF. Heart Rate Variability and Cardiac Vagal Tone in Psychophysiological Research Recommendations for Experiment Planning, Data Analysis, and Data Reporting. Front Psychol. 2017 Feb 20;8.

77. Gillie BL, Thayer JF. Individual differences in resting heart rate variability and cognitive control in posttraumatic stress disorder. Front Psychol [Internet]. 2014 Jul 15 [cited 2016 Oct 28];5. Available from:

http://www.ncbi.nlm.nih.gov/pmc/articles/PMC4097943/

78. Müller MP, Hänsel M, Fichtner A, Hardt F, Weber S, Kirschbaum C, et al. Excellence in performance and stress reduction during two different full scale simulator training courses: a pilot study. Resuscitation. 2009 Aug;80(8):91924.

79. Krage R, Zwaan L, Len LTS, Kolenbrander MW, Groeningen D van, Loer SA, et al. Relationship between non-technical skills and technical performance during cardiopulmonary resuscitation: does stress have an influence? Emerg Med J. 2017 Nov 1;34(11):728-33.

80. Huang C-J, Webb HE, Zourdos MC, Acevedo EO. Cardiovascular reactivity, stress, and physical activity. Front Physiol. 2013 Nov 7;4.

81. Hall KS, Hoerster KD, Yancy WS. Post-traumatic stress disorder, physical activity, and eating behaviors. Epidemiol Rev. 2015;37:103-15.

82. Narita-Ohtaki R, Hori H, Itoh M, Lin M, Niwa M, Ino K, et al. Cognitive function in Japanese women with posttraumatic stress disorder: Association with exercise habits. J Affect Disord. 2018 15;236:306-12.

83. Patterson PD, Klapec S, Weaver MD, Guyette FX, Platt TE, Buysse DJ. Differences in paramedic fatigue before and after changing from a 24-hour to 8-hour shift schedule: A case report. Prehospital Emerg Care Off J Natl Assoc EMS Physicians Natl Assoc State EMS Dir. 2016;20(1):132-6.

84. Coffey B, MacPhee R, Socha D, Fischer SL. A physical demands description of paramedic work in Canada. Int J Ind Ergon. 2016 May;53:355-62.

85. Paramedic Chiefs of Canada (PCC), Ad-hoc Commitee on Operational Stress Injury. Operational Stress Injury in Paramedic Services: A Briefing to the Paramedic Chiefs of Canada [Internet]. 2014 Jun p. 44. Available from: https://www.paramedicchiefs.ca/docs/PCC\%20Ad\%20hoc\%20Committee\%20on\%20Stress\%20Injury\%20Report.doc

86. Oliphant R. Healthy minds, safe communities: Supporting our public safety officers through a National strategy for Operational Stress Injuries. Ottawa (ON): House of Commons, Parliament of Canada; 2016 Oct p. 50. Report No.: 42nd Parliament, 1st Session.

87. CSA Group. Psychological health and safety in the paramedic service organization. Toronto (ON); 2018 Mar p. 88. Report No.: Z1003.1.18.

\section{Tables}


Table 1.

Results of 19 experienced paramedics on health measurement tools, health impairments and simulated patient-care intervention performance.

ID Physical

\begin{tabular}{|c|c|c|c|c|c|c|c|c|c|c|}
\hline \multicolumn{3}{|c|}{ CVD } & \multicolumn{3}{|c|}{ MSD } & \multicolumn{4}{|c|}{ PTSD } & GAD \\
\hline Diag & YM CA & SD NN50 & Diag & FMS & $\mathrm{NQ}$ & Diag & PCLC & RSES 22 & SOC 13 & Diag GAD7 \\
\hline
\end{tabular}

Failed patient-care simulation

\begin{tabular}{|c|c|c|c|c|c|c|c|c|c|c|c|c|}
\hline 1 & 1 & 1 & 1 & . & 1 & 1 & . & 1 & . & 1 & . & 1 \\
\hline 4 & . & . & . & . & . & 1 & 1 & 1 & 1 & . & . & . \\
\hline 6 & . & . & . & . & . & . & . & . & . & . & . & . \\
\hline 8 & . & 1 & 1 & . & 1 & . & . & . & 1 & . & . & . \\
\hline 10 & . & 1 & 1 & . & . & . & . & . & . & . & . & . \\
\hline 12 & . & 1 & . & . & . & . & . & . & . & . & . & . \\
\hline 13 & . & . & 1 & . & . & . & . & . & . & 1 & . & 1 \\
\hline 14 & . & 1 & . & . & 1 & 1 & . & 1 & 1 & 1 & . & . \\
\hline 18 & . & 1 & . & 1 & 1 & 1 & . & . & . & . & . & 1 \\
\hline$\underset{(\%)}{\text { Sum }}$ & $\begin{array}{c}1 \\
(11)\end{array}$ & $\begin{array}{c}6 \\
(67)\end{array}$ & $\begin{array}{c}4 \\
(44)\end{array}$ & $\begin{array}{c}1 \\
(11)\end{array}$ & $\begin{array}{c}4 \\
(44)\end{array}$ & $\begin{array}{c}4 \\
(44)\end{array}$ & $\begin{array}{c}1 \\
(11)\end{array}$ & $\begin{array}{c}3 \\
(33)\end{array}$ & $\begin{array}{c}3 \\
(33)\end{array}$ & $\begin{array}{c}3 \\
(33)\end{array}$ & $\begin{array}{c}0 \\
(0)\end{array}$ & $\begin{array}{c}3 \\
\text { (33) }\end{array}$ \\
\hline
\end{tabular}

Passed patient-care simulation

\begin{tabular}{|c|c|c|c|c|c|c|c|c|c|c|c|c|}
\hline 2 & . & 1 & 1 & . & . & . & . & . & . & . & . & . \\
\hline 3 & 1 & 1 & 1 & . & 1 & 1 & . & . & . & . & . & . \\
\hline 5 & . & 1 & . & . & . & . & . & . & . & . & . & . \\
\hline 7 & . & 1 & . & . & 1 & . & . & . & . & . & . & . \\
\hline 9 & 1 & 1 & 1 & . & 1 & 1 & . & . & . & . & . & . \\
\hline 11 & 1 & 1 & . & . & . & . & . & . & . & . & . & . \\
\hline 15 & . & 1 & . & . & . & . & . & . & . & . & . & . \\
\hline 16 & . & 1 & . & 1 & 1 & 1 & . & . & . & . & . & . \\
\hline 17 & . & . & . & . & . & . & . & . & . & . & . & . \\
\hline 19 & . & . & . & 1 & 1 & 1 & . & . & . & . & . & $\cdot$ \\
\hline $\begin{array}{c}\text { Sum } \\
(\%)\end{array}$ & $\begin{array}{c}3 \\
(30)\end{array}$ & $\begin{array}{c}8 \\
(80) \\
\end{array}$ & $\begin{array}{c}3 \\
(30) \\
\end{array}$ & $\begin{array}{c}2 \\
(20) \\
\end{array}$ & $\begin{array}{c}5 \\
(50) \\
\end{array}$ & $\begin{array}{c}4 \\
(40) \\
\end{array}$ & $\begin{array}{c}0 \\
(0) \\
\end{array}$ & $\begin{array}{c}0 \\
(0)\end{array}$ & $\begin{array}{c}0 \\
(0)\end{array}$ & $\begin{array}{c}0 \\
(0)\end{array}$ & $\begin{array}{c}0 \\
(0)\end{array}$ & $\begin{array}{c}0 \\
(0) \\
\end{array}$ \\
\hline $\begin{array}{r}\text { Total } \\
\text { (\%) }\end{array}$ & $\begin{array}{c}4 \\
(21)\end{array}$ & $14(74)$ & $\begin{array}{c}7 \\
(37)\end{array}$ & $\begin{array}{c}3 \\
(16)\end{array}$ & $\begin{array}{c}9 \\
(47)\end{array}$ & $\begin{array}{c}8 \\
(42)\end{array}$ & $\begin{array}{c}1 \\
(5)\end{array}$ & $\begin{array}{c}3 \\
(16)\end{array}$ & $\begin{array}{c}3 \\
(16)\end{array}$ & $\begin{array}{c}3 \\
(16)\end{array}$ & $\begin{array}{c}0 \\
(0)\end{array}$ & $\begin{array}{c}3 \\
(16)\end{array}$ \\
\hline
\end{tabular}

(Value of 1) Participant identified positively with a tool; (Highlighted gray) Participant considered with a at-risk of health condition (CVD, MSD, PTSD or GAD); (SIM) Patient-care simulation; (Diag) Selfreported diagnosis; (CVD) Elevated risk of cardiovascular diseases; (MSD) Elevated risk of musculoskeletal disorders; (PTSD) Elevated symptoms of post-traumatic stress disorders; (GAD) Elevated symptoms of generalized anxiety disorders. (NQ) Nordic questionnaire; (FMS) functional movement screen; (YMCA) step test; (SDNN50) SDNN value below 50 ms; (PCL-C) civilian version of PTSD check list; (RSES-22) responses to stressful experiences scale; (SOC13) sense of coherence; (GAD-7) generalized anxiety disorders. 
Table 2 .

Table of occupational performance of 19 experienced paramedics on simulated clinical task. Patientcare performance are ranked from lowest to highest on total score.

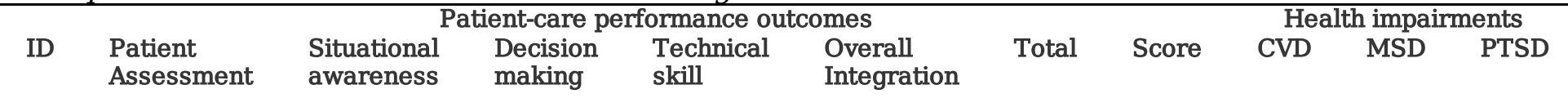

\begin{tabular}{|c|c|c|c|c|c|c|c|c|c|c|}
\hline 8 & 1 & 1 & 1 & 1 & 1 & 5 & Failed & 1 & & \\
\hline 12 & 1 & 1 & 1 & 1 & 1 & 5 & Failed & & & \\
\hline 14 & 1 & 1 & 1 & 1 & 1 & 5 & Failed & & 1 & 1 \\
\hline 13 & 2 & 2 & 1 & 1 & 1 & 7 & Failed & & & \\
\hline 10 & 1 & 2 & 2 & 2 & 2 & 9 & Failed & 1 & & \\
\hline 18 & 2 & 2 & 2 & 1 & 2 & 9 & Failed & & 1 & \\
\hline 6 & 2 & 2 & 2 & 2 & 2 & 10 & Failed & & & \\
\hline 1 & 3 & 3 & 1 & 2 & 2 & 11 & Failed & 1 & 1 & 1 \\
\hline 4 & 4 & 2 & 3 & 3 & 3 & 15 & Failed & & & 1 \\
\hline 7 & 4 & 3 & 4 & 3 & 4 & 18 & Passed & & & \\
\hline 9 & 4 & 3 & 4 & 3 & 4 & 18 & Passed & 1 & 1 & \\
\hline 11 & 4 & 3 & 3 & 4 & 4 & 18 & Passed & 1 & & \\
\hline 3 & 4 & 4 & 4 & 3 & 4 & 19 & Passed & 1 & 1 & \\
\hline 19 & 3 & 4 & 4 & 4 & 4 & 19 & Passed & & 1 & \\
\hline 2 & 4 & 4 & 4 & 4 & 4 & 20 & Passed & 1 & & \\
\hline 16 & 4 & 5 & 4 & 3 & 4 & 20 & Passed & & 1 & \\
\hline 17 & 4 & 4 & 5 & 5 & 5 & 23 & Passed & & & \\
\hline 15 & 4 & 5 & 5 & 5 & 5 & 24 & Passed & & & \\
\hline 5 & 5 & 5 & 5 & 5 & 5 & 25 & Passed & & & \\
\hline
\end{tabular}

Note. The table is ranked in an increasing order, from the lowest to the highest total score. The total scores were calculated from the 5 criteria assessed while the patient-care intervention. (Highlighted gray) Participants who had failed the criteria (cut-off point is 3/6); (Value of 1) participant considered with at-risk of health impairment (CVD, MSD, PTSD); (CVD) Elevated risk of cardiovascular diseases; (MSD) Elevated risk of musculoskeletal disorders; (PTSD) Elevated symptoms of post-traumatic stress disorders;

\section{Appendix A}

A summary of the criteria assessed are described as follow:

- Patient assessment: organized approach; selects appropriate assessment strategy; focused assessment is thorough and complete; evaluates and interprets assessment findings; obtains comprehensive associate history; completes timely follow-up assessment.

- Situational awareness: recognizes routine situations and settings in which safety problems may arise; exercises vigilance on safety issues; gathers the appropriate amount of information; recognizes actionable information; continually observes the whole environment; adapts to task demands and changes effectively; demonstrates safety practices that reduce the risk of adverse events.

- Decision making: selects the most appropriate solution for a given context; responds effectively by means of efficient task and process management; displays critical thinking, including situational awareness and an awareness of cognitive biases in decision making; demonstrates a process of sound decision-making, understanding where the process can be challenged and corrected; makes decisions based on evidence.

- Technical skill: practices within scope of practice for level; does not attempt skills that they are unfamiliar or incompetent in despite scope of practice; follows safe work procedures for all skills; obtains consent as appropriate for all skills; displays technical competency in all skills; assesses efficacy of intervention and modifies plan as necessary; initiates skill in timely fashion and appropriate setting; adequately prepares all necessary resources prior to initiating skill; performs skills in logical order; selects appropriate skills. 
- Overall integration: performance is consistent with professional standards; patient safety is main priority in all decisions and interventions; displays confidence in decision making; technically competent in skills; demonstrates clear and concise communication abilities in all settings; effectively utilizes resources both human and technical.

\section{Figures}

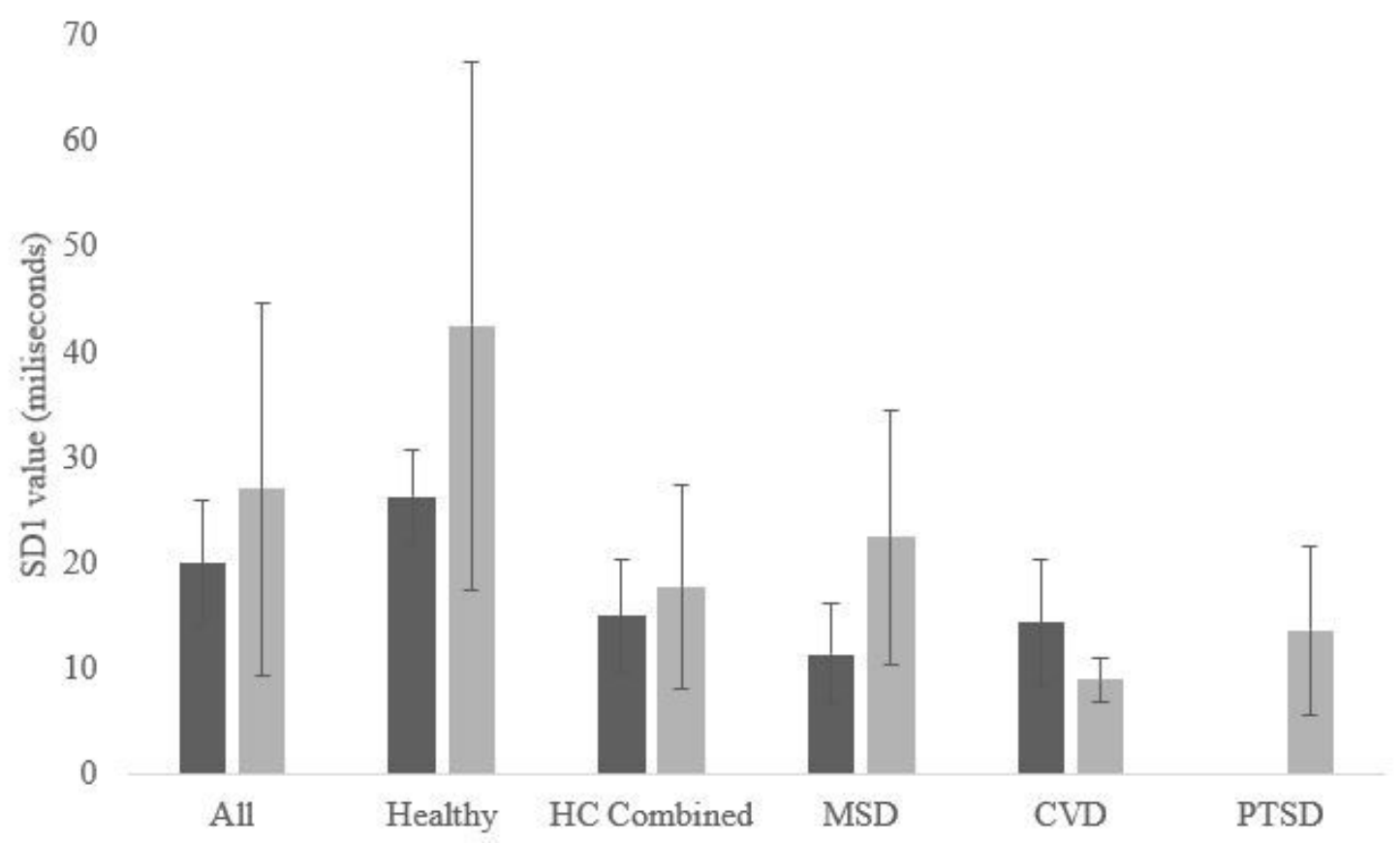

\section{Figure 1}

Tonic HRV value. Illustration of means and 95\% confidence interval errors bars of vagal activity during the baseline period. (Dark grey) Participants who passed the patient-care simulation; (Light grey) Participants who failed the patientcare simulation. (All) All participants; (Healthy) Participants without health impairments; (HC combined) All participant with health impairment combined; (MSD) Participants identified with elevated risk of musculoskeletal disorders; (CVD) Participants identified with elevated risk of cardiovascular diseases; (PTSD) Participants identified with elevated symptoms of post-traumatic stress; It is noted that no participant identified with PTSD had succeed the patient-care simulation. 


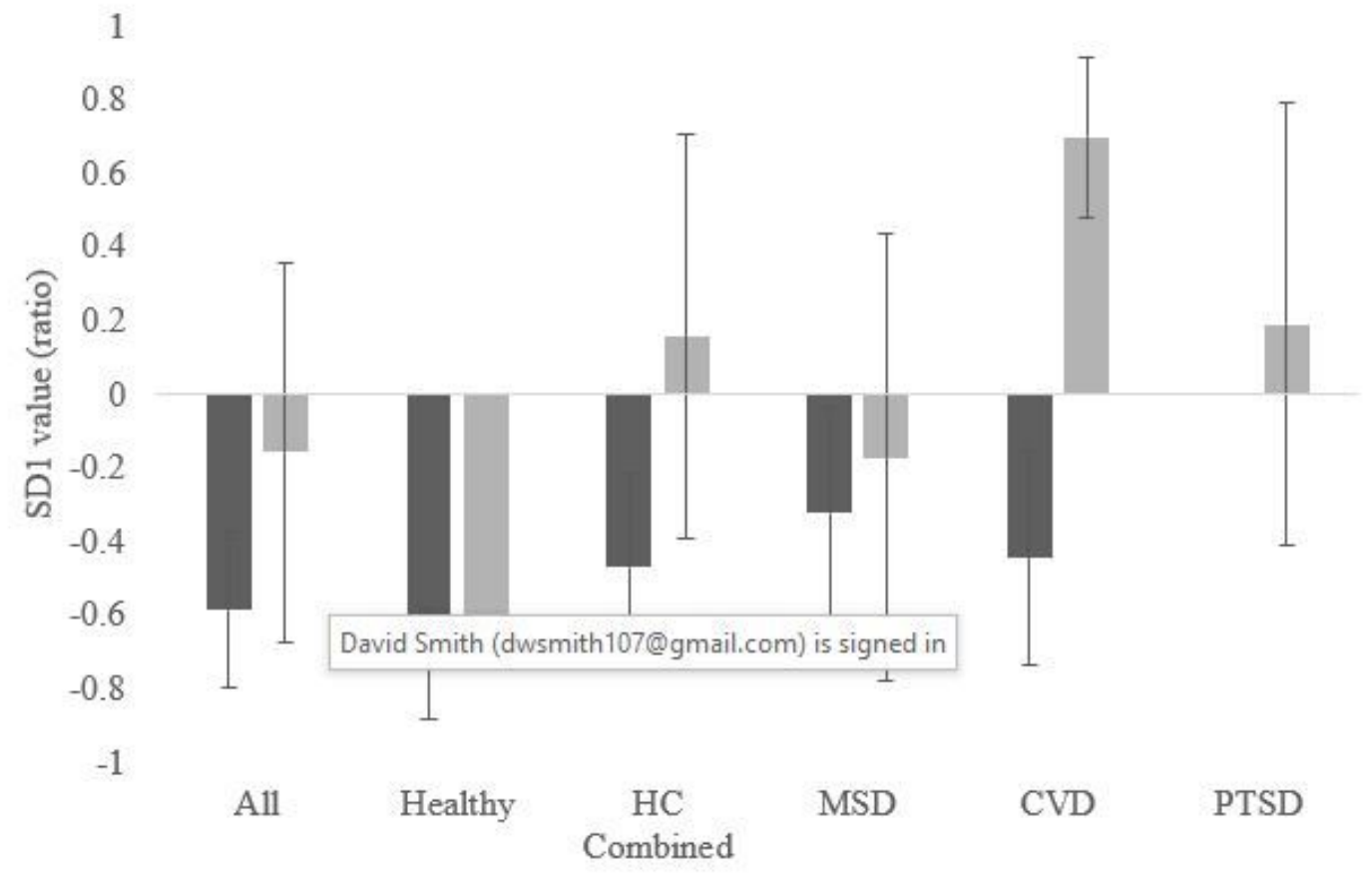

\section{Figure 2}

Phasic HRV values for the assessment part of patient-care simulation. Phasic HRV (or reactivity HRV) was calculated from the difference between the HRV values during the assessment part of the patient-care simulation and baseline period. The values are presented in ratio, where negative values mean that the simulation parts created a higher activity than the physiological baseline period. Illustration of means and 95\% confidence interval errors bars. (Dark grey) Participants who passed the patient-care simulation; (Light grey) Participants who failed the patient-care simulation. (All) All participants; (Healthy) Participants without health impairments; (HC combined) All participant with health impairment combined; (MSD) Participants identified with elevated risk of musculoskeletal disorders; (CVD) Participants identified with elevated risk of cardiovascular diseases; (PTSD) Participants identified with elevated symptoms of post-traumatic stress; It is noted that no participant identified with PTSD had succeed the patient-care simulation. 


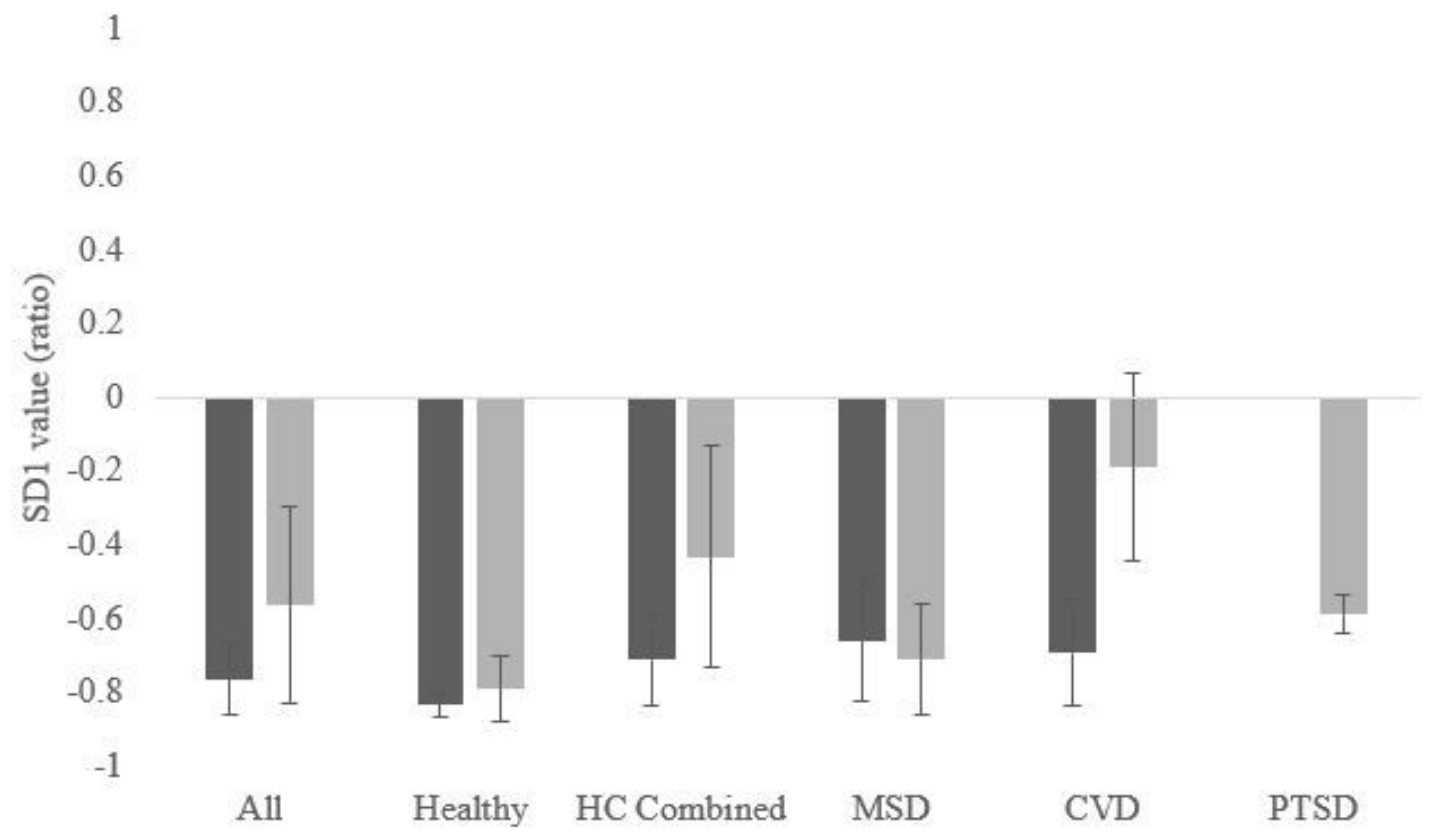

\section{Figure 3}

Phasic HRV values for the intervention part of patient-care simulation. Phasic HRV (or reactivity HRV) was calculated from the difference between the HRV values during the intervention part of the patient-care simulation and baseline period. The values are presented in ratio, where negative values mean that the simulation parts created a higher activity than the physiological baseline period. Illustration of means and 95\% confidence interval errors bars. (Dark grey) Participants who passed the patient-care simulation; (Light grey) Participants who failed the patient-care simulation. (All) All participants; (Healthy) Participants without health impairments; ( $\mathrm{HC}$ combined) All participant with health impairment combined; (MSD) Participants identified with elevated risk of musculoskeletal disorders; (CVD) Participants identified with elevated risk of cardiovascular diseases; (PTSD) Participants identified with elevated symptoms of post-traumatic stress; It is noted that no participant identified with PTSD had succeed the patient-care simulation. 